\title{
EVALUATION OF INLET MANAGEMENT PRACTICES AT NAVIGATION INLETS IN SOUTHWEST FLORIDA, USA
}

\author{
Mohamed Dabees, ${ }^{1}$ and Brett D. Moore ${ }^{1}$ \\ This paper describes numerical modeling of long-term evolution of inlet systems in southwest and central Florida. \\ The paper discusses a general methodology developed following four case studies and application to the case study of \\ Gordon Pass in southwest Florida. The case study of Gordon Pass demonstrates the importance of considering large \\ temporal and spatial scales in evaluating morphologic response to inlet management practices. The results describe \\ the evolution of Gordon Pass from 1930 to present. The analysis begins with natural conditions that existed before \\ dredging or inlet modifications and investigates how inlet evolution can be influenced by navigation improvements \\ and provides tools to evaluate alternatives. \\ Keywords: Coastal Processes, Dredging, Ebb Shoal, Erosion, Florida, Inlet Evolution, Inlet Reservoir Model, \\ Gordon Pass, Morphology, Regional Sand Management, Sediment Transport, Tidal Inlets.
}

\section{INTRODUCTION}

During the course of development during the past century, numerous tidal inlets have undergone improvements to stabilize their navigation channels. Inlet navigation improvements include maintenance dredging and construction of stabilizing structures such as jetties and terminal groins. Up-drift impoundments and downdrift erosion has been a persistent consequence for navigation inlets with long jetties. Until the 1970s, inlet management practice in Florida included offshore disposal of dredged material, which interrupted natural bypassing and reduced sand supply to downdrift beaches. Chronic erosion downdrift of dredged inlets led to several inlet management studies throughout Florida in the 1980s and 1990s. Since that time, in cases of inlets with long jetties, a common practice to mitigate downdrift erosion has been through mechanical bypassing. Additionally, placement of maintenance dredged material on the adjacent downdrift beaches is now a common practice for all inlets. Ongoing response of adjacent shorelines to existing inlet structures and the lack of tools to assess future consequences have resulted in the potential for continuing adverse impacts, a valid concern to regulatory agencies. As a result, regulatory agencies in Florida have resisted permitting of new structures on unarmored inlets and preferred maintenance dredging of navigation channels and strategic placement of the disposal material on the beach to mitigate for potential impacts. In the absence of inlet stabilization structures, frequent dredging may be necessary to stabilize channel locations and maintain depths sufficient for reliable navigation in critical shoaling areas. Beach erosion and channel migration are among the consequences of cumulative effects of channel dredging on inlets without stabilization structures. Inlet management programs continue to evaluate their inlet management policies and implementation to safeguard navigation and reduce impacts to adjacent beaches. This paper discusses evaluation of long-term effects of navigation improvements on inlet and beach morphologic response to various navigation inlets in southwest and central Florida.

\section{CASE STUDIES}

The general methodology discussed in this paper was developed based on four case studies of navigation inlets in southwest and central Florida with various inlet stabilization scenarios. Figure 1 shows a location map of the four inlets used as case studies. The case studies include an inlet without stabilization structures (Wiggins Pass), an inlet with two long jetties (Venice Inlet), and two inlets with one jetty each. The two inlets with one long jetty each include a case where the jetty is on the updrift side (Longboat Pass) and the other case where the jetty is on the downdrift side (Gordon Pass). The four navigation inlets are located within $200 \mathrm{Km}$ along southwest Florida gulf coast.

The majority of the Florida gulf coast is made up of systems of barrier islands separated by multiple inlets sharing the tidal prism of large bay areas. In such cases, analysis of large spatial scales or regional modeling of the entire system is necessary in order to evaluate the conditions at any one inlet. Additionally, morphology responses to natural and anthropogenic changes near tidal inlets require modeling and evaluation of large time scales. Dabees and Kraus (2004, 2005, and 2008) presented a general methodology for modeling tidal inlets evolution and examining the

\footnotetext{
${ }^{1}$ Humiston \& Moore Engineers, Naples, FL, 34110, USA- Email: md@humistonandmoore.com
} 
morphologic response of cumulative inlet dredging at several inlets in southwest and central Florida. The methodology is based on various levels of data analysis and the application of the Inlet Reservoir Model (IRM) (Kraus 2000a, 2000b) that simulates long-term evolution of inlet shoals. This methodology includes numerical modeling and data analysis for various spatial and time scales to evaluate the evolution of the inlet, existing conditions, and effects of alternatives for a proposed design.

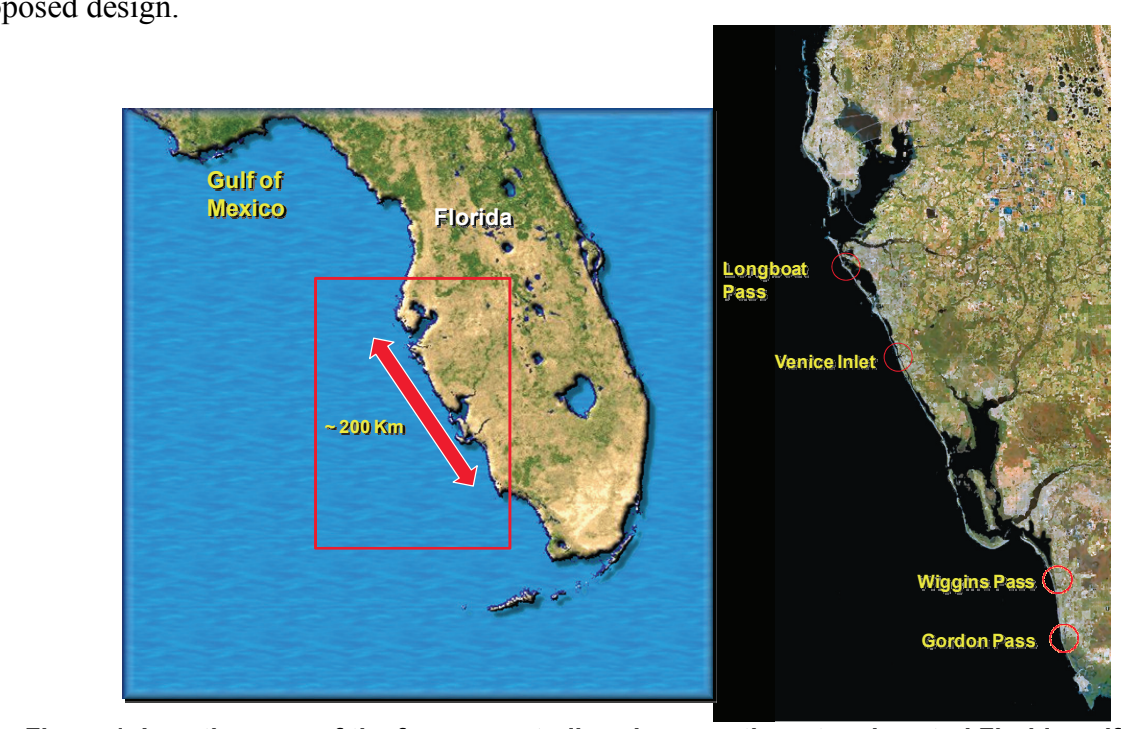

Figure 1. Location map of the four case studies along southwest and central Florida gulf coast.

This methodology was applied for each of the four navigation inlets included in this paper. The analysis includes documented inlet evolution, and modeling of regional hydrodynamics, waves, and sediment transport at various times simulating principal stages during the evolution of each inlet system. Process-based modeling results serve as input to the IRM to quantify volumetric change and bypassing rates between the different morphologic features that comprise each inlet shoal system through three main temporal stages: conditions describing how each system naturally evolved prior to any dredging, jetty construction or inlet modifications and effects of jetty construction and/or inlet dredging to describe ongoing processes, and potential alternative inlet management strategies to reduce inlet impacts and provide a basis for future management policy decisions. This paper discusses in some detail the Gordon Pass case study. The Longboat Pass, Venice Inlet and Wiggins Pass case studies are discussed in Dabees and Kraus (2008), Dabees and Moore (2011), and Humiston \& Moore (2007), respectively. Evaluation of the tidal inlet channel migration and dredging effects for Venice Inlet, Longboat Pass and Wiggins Pass are discussed in Dabees et al (2011).

\section{Gordon Pass case study}

Gordon Pass is located in City of Naples, Florida. It is part of a federally authorized navigation project. This inlet has been stabilized with a terminal groin and a jetty on the north and south banks of the pass, respectively in the 1960's. Historical survey data show that from 1930's to 1957 prior to the commencement of dredging, the Gordon Pass shoal system had been growing. This growth was in response to increases in tidal prism from the closure of an inlet that existed approximately 1 mile south of Gordon Pass in the 1940's, and from development of tributary waterways, primarily development along Naples Bay and the Port Royal Canal system. In the 1960's the Golden Gate canal system was connected to the north end of Naples Bay resulting in a significant increase in freshwater flowing through the Bay system and out Gordon Pass. The data also shows that the inlet ebb shoal began decreasing in volume in the 1990's as a result of the cumulative navigation maintenance dredging. From 1960 to 2003, the inlet was dredged 7 times at an average interval of approximately 7 years. The study shows that the cumulative effects of management of the inlet system through maintenance dredging and downdrift beach disposal have been insufficient in addressing the erosion of adjacent beaches to the inlet. 
Figure 2 shows the contour map of the inlet system in the 1930's, 1950's and present conditions. The 1930's represent conditions prior to any development in the bay and inlet system. The figure is based on the earliest bathymetric data available from the 1930's by the U.S. Coast and Geodetic Surveys. The surveys of the 1930's have provided means to quantify the natural morphologic features at that time and includes the conditions in the nearshore and on adjacent beaches. At that time there was no apparent offset between the shorelines north and south of the pass. The adjacent beaches to Gordon Pass had a wide shallow swash zone on both sides of the inlet. The wide tidal swash and ebb shoal features provided a natural means to bypass sand from one side of the inlet to the other.

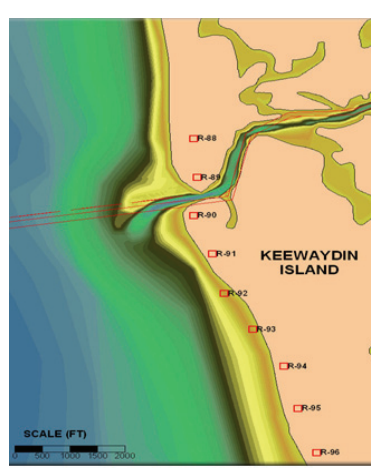

1930

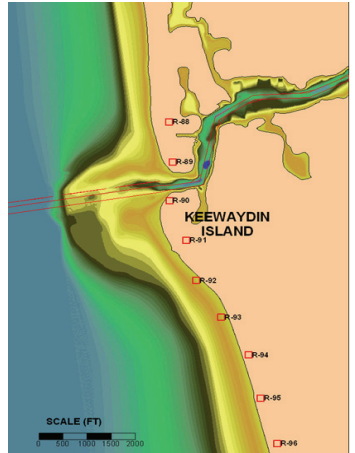

1957

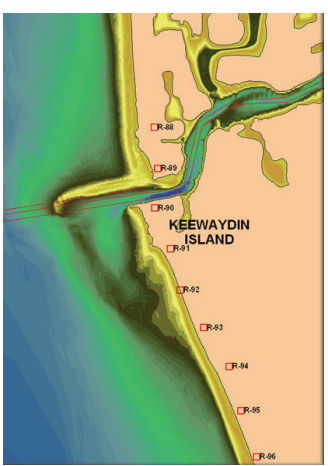

2008

Figure 2. Gordon Pass bathymetry at various temporal stages

The 1957 bathymetry represents the 1950 's prior to the navigation improvements to the pass and inland bay in the 1960's. The 1950's conditions indicate significant increase in the size of the ebb shoal on both sides of the inlet. During the 1940's and 1950's upland and canal developments along the interior bay system increased the bay area and tidal prism flowing through Gordon Pass. In response, the Gordon Pass ebb shoal volume increased towards a larger equilibrium than its equilibrium size prior to development along Naples Bay. The increased capacity of the ebb shoal may have been a factor in the beach erosion north of Gordon Pass during the 60's which resulted in various shore protection structures. Series of rock groins were constructed along Naples beach north of the inlet in 1950's and 1960's followed by installation of seawalls.

In the early 1960's Gordon Pass became an authorized Federal Navigation Channel, and the inlet channel was stabilized with a jetty at the south side to reduce sand loss back to the inlet as a result of anticipated sand placement of dredged sand on Keewaydin Island. At that time a rock groin field already existed north of the inlet. Since the initial dredging in 1962, the inlet has been maintained with periodic dredging on an average 7-year interval. 
Modeling and Analysis of Gordon Pass and North Keewaydin Island

\section{Regional Hydrodynamics}

Regional hydrodynamic modeling for various temporal conditions from the 1930's to present, involving various stages of changes in tidal prism, was done using the Advanced Circulation Model (ADCIRC, Luettich et al.1991). The model covered the Gordon Pass tributary area from the Gordon River including, Naples Bay, Port Royal Canals, Dollar Bay, Bartell Bay and Shell Bay south to the north boundaries of Rookery Bay, as illustrated in Figures 3 and 4. The figure shows the model coverage at different temporal stages indicating the changes in bay area. The Gulf of Mexico coverage included an area that extends approximately 10 miles alongshore and 5 miles offshore. The model was then run for the varying temporal conditions from 1930 to 2007 to quantify changes in tidal prism at three different times during evolution of the system. The temporal conditions included 1930's, 1970's, and present conditions.

All simulations were performed using the same forcing conditions (time series of astronomical tides at the model boundary) to allow comparison of the tidal prism between different years. Modeling the regional hydrodynamics for the 1930's conditions was done to assess the natural dynamics of Gordon Pass bay system and its inlet prior to the $20^{\text {th }}$ century development of the Naples Bay area. The temporal stage of the 1970's represented the conditions post the navigation improvements to the pass and inland bay in the 1960's. The temporal stage in the 1990's represented the present conditions. All three temporal stages provided boundary conditions used for detailed modeling of waves and current interactions for Gordon Pass and the adjacent beaches.

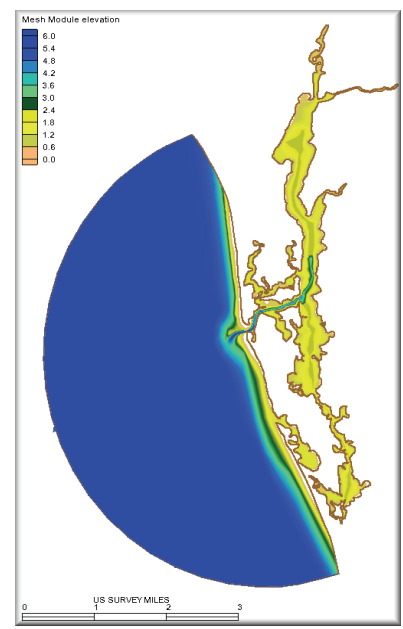

Fig 3. 1930's model coverage

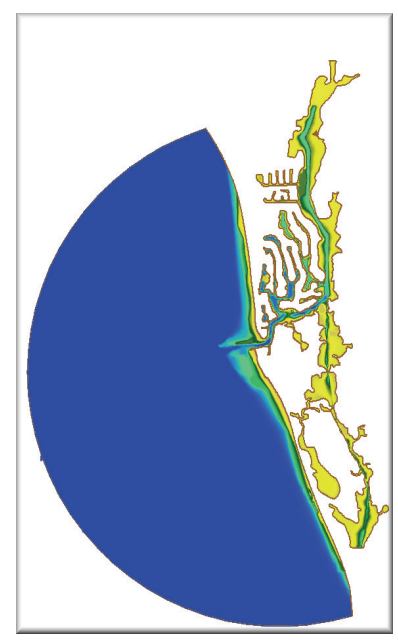

Fig 4. 2000's model coverage

\section{Wave and Current Interaction Modeling and Analysis}

Detailed wave and sediment transport modeling with the Coastal Modeling System (CMS) (Buttolph et al. 2006) was used to simulate wave and current interaction and sediment pathways for conditions prior to and following the 1960's initial dredging, and for evaluating the long-term effects of the cumulative dredging of the pass on sand supply to the north end of Keewaydin Island. The model was run for combinations of predominant wave conditions and tides to gain an understanding of the patterns of littoral transport in and around the inlet system. The detailed model simulated the flow patterns for the temporal conditions of the 1930's prior to any development, the 1970's for the post navigation improvement including bay improvements, and the 1990's for present conditions, which would include the effects of the cumulative dredging. 
Model simulations were performed using boundary conditions from the regional model from the corresponding temporal stage. Model runs for storm waves during spring and average tide conditions were simulated for the three temporal stages. The wave conditions included wave directions from northwest (NW), West (W) and southwest (SW) to evaluate representative flow patterns for each condition and to prepare inputs for the long-term Inlet Reservoir Model. The NW wave condition is selected for discussion here. Figure 5 shows the model results for the 1930's conditions for a NW wave storm event during typical ebb and flood flow stages. The figure indicates the velocity where magnitudes are above 0.1 meters per second, flow directions, and extents of areas of flow velocities that are strong enough to result in active sand transport. Redcolored areas indicate velocities greater than the critical velocity for sediment movement $(\sim 1 \mathrm{~m} / \mathrm{s})$. The 1930's results indicate the natural sand bypassing patterns across a natural inlet. The 1930's conditions show the alignment of the adjacent beaches on both sides of the inlet with large swash zones in addition to the natural ebb features which provided natural uninterrupted sand bypassing across the inlet.
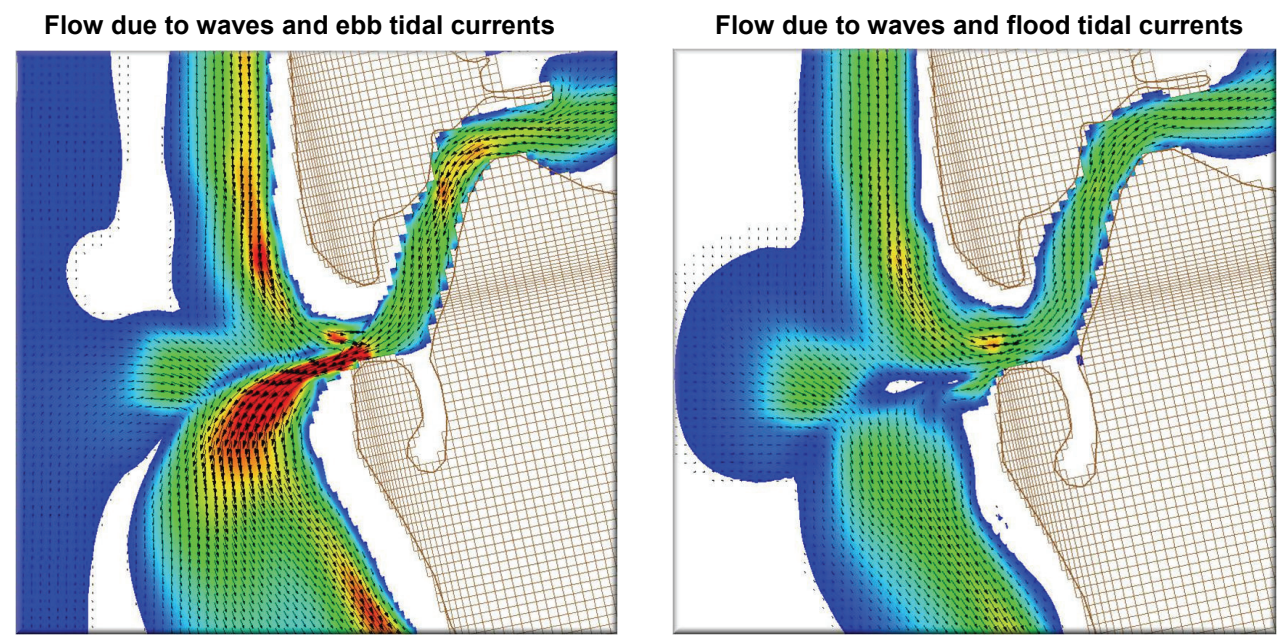

Figure 5. Wave and current interaction at ebb and flood tidal stages for the 1930's conditions

Figure 6 shows a simplified schematic of the natural sand bypassing patterns and sediment pathways prior to the inlet and bay development and changes discussed herein. The sediment pathways at that time showed the south lobe of the ebb shoal sheltering the northern portion of Keewaydin Island and providing a net northward nearshore transport from attachment bar toward the north end of the island. This is commonly referred to as the downdrift reversal since the net sediment transport for this region is north to south; however, the transport reverses to the north just downdrift of the inlet due to the presence and effect of the shoal.

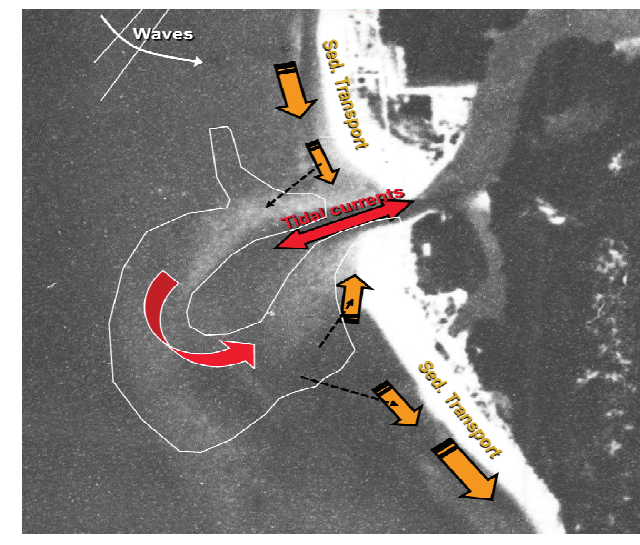

Figure 6. Schematic of sediment pathways for the 1930's conditions 
Figure 7 shows the model results for the (2000's) present conditions for a NW wave storm event during typical ebb and flood flow stages. The cumulative dredging of the navigation channel reduced the size of the ebb shoal while the increased flow from the interior changes along Naples Bay, and the jetty at the north end of Keewaydin Island steepened and hardened the south bank of Gordon Pass and guided the ebb jet further offshore prevented nearshore sedimentation at the beach immediately south of the pass. The placement of the dredging disposal on the beach immediately south of the jetty may have provided short term mitigation for the lack of natural bypassing at the time. The model results showed that during flood flow the high crested long jetty causes water to pile up then flow out next to the jetty. This in-conjunction with the high velocities from the increased ebb flow resulted in scouring a secondary channel directed south southwest (SSW) extending the area of sediment deposition further south of the jetty. This, in addition to the deflation of the south lobe of the ebb shoal and the changes in sediment pathways of the sand bypass resulted in reduced sand supply to the shoreline immediately south of the jetty. At this point, the primary source of sand to the north end of Keewaydin Island is through mechanical sand placement. This was evident from the rapid erosion rates at the north section of the beach since the early nineties.

Flow due to waves and ebb tidal currents

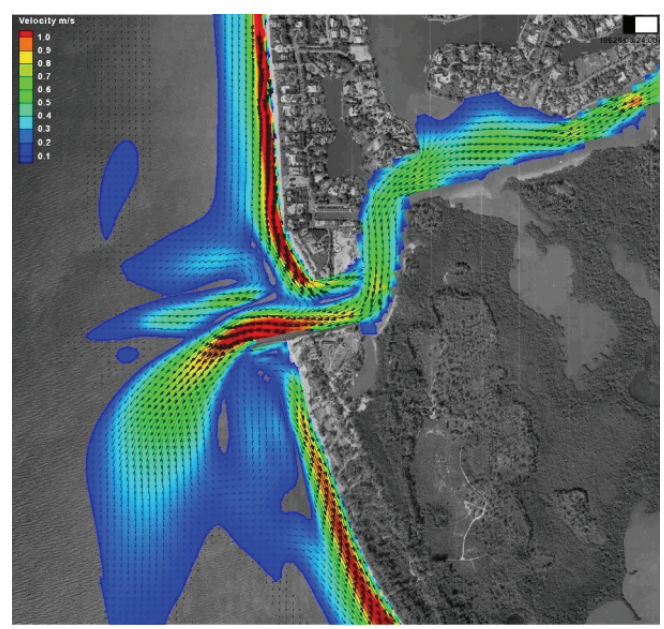

Flow due to waves and flood tidal currents

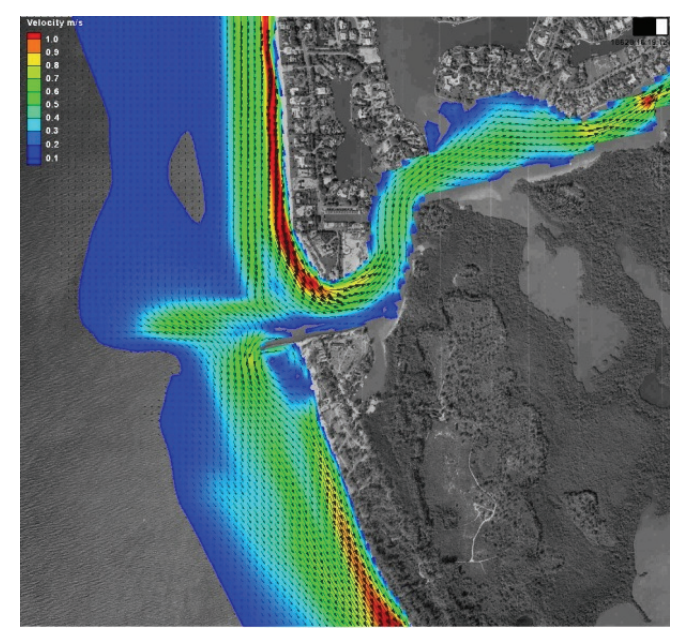

Figure 7. Wave and current interaction at ebb and flood tidal stages for the 2000's conditions

Figure 8 shows a schematic of the sediment pathways for the 2000's (present) conditions. The sediment pathways show the ebb tide flowing through the main channel and the secondary channel. During calm weather, tidal flow follows the maintained channel alignment. During storm wave conditions with southward littoral drift, the ebb tide flows towards the SSW in the secondary channel with littoral material depositing further south from the inlet. The schematic also indicates the interruption of natural sand bypassing as a result of the cumulative effect of the maintenance dredging and deflation of the south lobe of the ebb shoal.

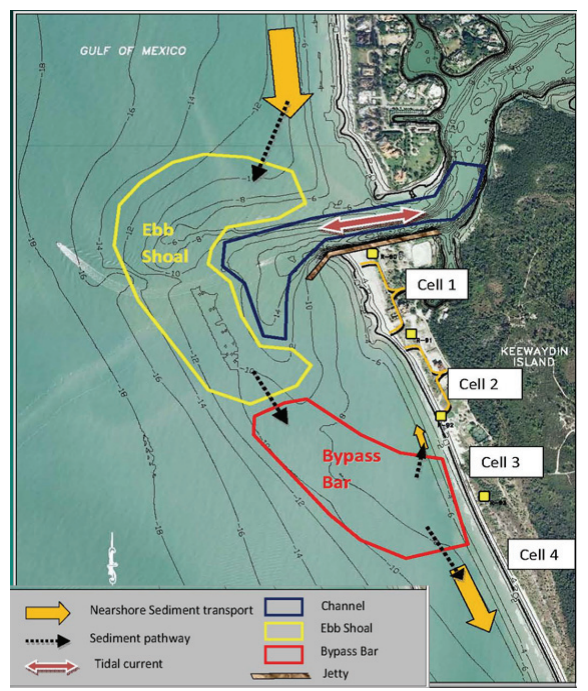

Figure 8. Schematic of sediment pathways for the 2000's conditions 


\section{Inlet Reservoir Model Analysis for Gordon Pass}

The Inlet Reservoir Model calculates sediment transport rates and volume change of identified morphologic features and bypassing rates for an inlet. It is applied here for the Gordon Pass tidal shoal complex. The first step is to identify sediment pathways across distinct morphologic ebb and flood features that form the shoal complex. In a typical wave-dominated inlet, there would be three distinct ocean-side features: an ebb shoal, bypassing bar, and an attachment bar. The concept of the Inlet Reservoir Model (IRM) is based on the assumption that each feature has a maximum equilibrium sand-retention capacity that cannot be exceeded. The equilibrium capacity is primarily a function of tidal prism and potential sediment transport to the inlet; however it may also be influenced by inlet geometric changes such as those brought about by construction of jetties and channel dredging. Once a distinct ebb or flood morphologic feature has reached equilibrium capacity, all additional sediment transport to that feature will bypass to the next feature(s), until sediment eventually arrives at the downdrift side of the inlet, or is deposited in another location such as the channel or flood shoal. If a morphologic feature is partially full, it still provides partial bypassing, and the degree to which bypass occurs is a function of how close the feature is to its equilibrium size. The Inlet Reservoir Model therefore calculates growth of the shoals as a function of the littoral drift and equilibrium volumes of the shoals. It accounts for the long timescales of large morphologic feature changes and time delays in exchange of material between the features. It may therefore be used to estimate how dredging of an inlet shoal may affect bypassing, and how long it will take for a shoal to re-form, or recover, after dredging. Further information on the Inlet Reservoir Model can be found in Kraus (2000a, 2000b, 2002).

\section{Inlet Reservoir Model Setup and analysis}

The Gordon Pass ebb and flood shoal system has a history that is more complex than that of a typical inlet. The complexity is the result of changes in morphological features and sediment pathways as well as inlet navigation improvements and maintenance dredging. The bathymetric data, wave data, sediment transport and tidal hydrodynamic modeling results were evaluated to define sediment pathways for the evolution of Gordon Pass. Based on the CMS modeling results and documented elevation change, the sediment pathways and morphological features are represented as illustrated in Figure 9. The bathymetric data together with the modeling results defined 15 distinct morphologic features with varying coupling coefficients in the system. For both temporal stages of the inlet evolution, the following features have been present: beach cells, an ebb shoal, flood shoal, bypassing bars north and south of the inlet, and downdrift shoal or attachment bar

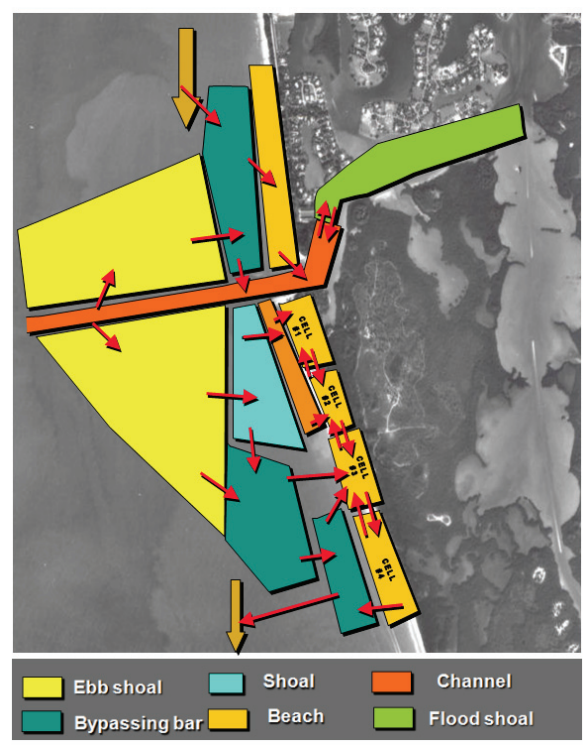

Figure 9. Schematic of IRM model setup for Gordon Pass on the south side of the inlet.

Sediment transport inputs for both north and south where calculated based on the 20 years (19801999) of wave data from nearest U.S. Army Corps of Engineers' Wave Information Study (WIS) station. Annual average potential transport rates were computed for the 20-year record. Additionally, high and low potential sediment transport rates were computed based on the 20-year average rates and standard deviations to account for sediment transport variability. 
The equilibrium volume of each feature was determined based on comparisons of available surveys and calculated volumes and rates of change for each feature. Although the features have varied somewhat in shape, location and size, they have been distinct in all available surveys and aerials. The input sediment transport rates were specified based on the sediment transport computations for each time period. The IRM model calculated volumes for average, maximum and minimum potential sediment transport rates for each of the morphologic features. The results were compared to actual measured volumes at times when data was available. In general, calculated volumes show good agreement with the observed and measured volumes and trends. The results describe the variation in volumetric change in response to the inlet improvements of the 1960's and interior bay improvements and subsequent maintenance dredging events up to present conditions.
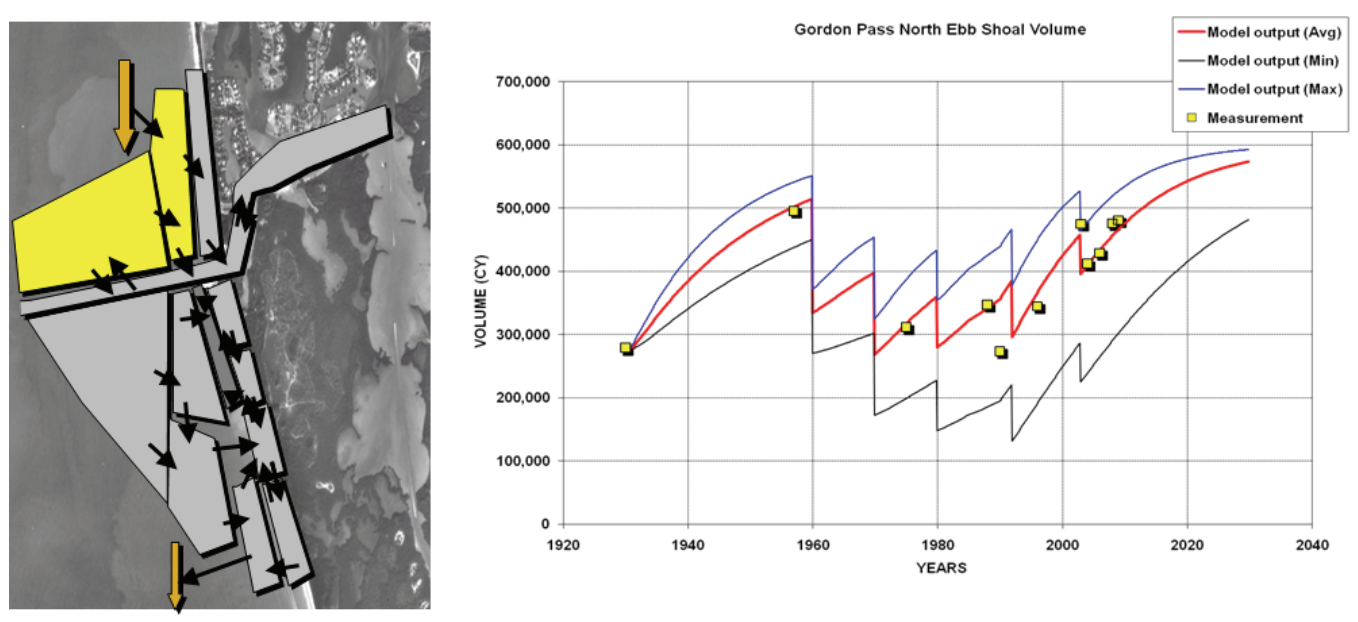

Figure 10. IRM model results and measured volumes for the north lobe of the ebb shoal

The model results for the north and south lobes of the shoal are discussed here. Figure 10 shows the model results for the total volume for the north lobe of the ebb shoal. This figure indicates reasonably good model agreement with measured volumes from available surveys, including the growth of the ebb shoal prior to the 1960's, followed by the effects of the dredging and partial recovery between dredging events. This figure shows that the rate of recovery of the north lobe of the ebb shoal has increased after the 1990's and that recovery still occurred following the 2003 dredging event.
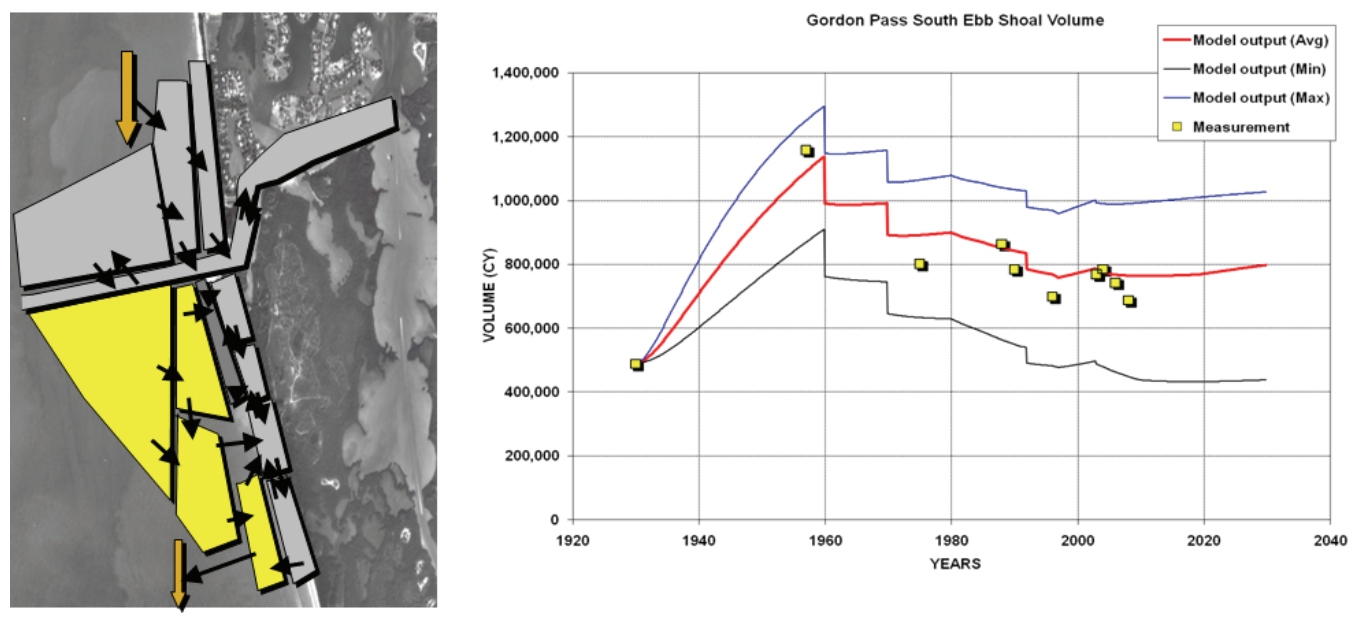

Figure 11. IRM model results and measured volumes for the north lobe of the ebb shoal 
The south lobe of the ebb shoal, however, has not recovered similar to the north lobe. Figure 11 shows results for the total volume for the south lobe of the ebb shoal. This figure indicates reasonably good model agreement with measured volumes from available surveys, including the growth of the ebb shoal prior to the 1960's, followed by the effects of the dredging and limited recovery between dredging events. While there have been periods of minor ebb shoal (south lobe) recovery, the overall trend has been limited recovery, particularly when compared with the recovery of the north lobe shown in Figure 10.

The IRM model results illustrate the evolution of the ebb delta from 1930, prior to the bay development and Gordon Pass stabilization, through the effects of the 1960's improvements, cumulative dredging effects, present conditions, and projection of future trends. The results indicate reasonably good model agreement with measurements from available surveys, including the increase in ebb shoal volume after the increase of bay area and tidal prism prior to the 1960's, followed by the effects of the dredging and partial recovery between dredging events. The model results also provide minimum and maximum limits of the morphologic feature volumes and bypassing rates at any point of time given the documented variability in sediment transport input.

\section{Application to downdrift beach evolution modeling}

This section describes the beach evolution modeling for the beach area immediately downdrift of Gordon Pass. The modeling was done to evaluate long-term shoreline evolution, explain an existing erosion problem, and provide a design tool for evaluating proposed erosion control alternatives. The varying levels of modeling including regional and detailed inlet flow modeling that were discussed earlier, were used to provide the inlet boundary conditions and sediment supply for the nearshore morphology model for the north end of Keewaydin Island. The results of the Inlet Reservoir Model provided the inlet bypassing boundary condition for the nearshore long-term beach morphology model NLINE (Dabees and Kamphuis, 2000).

Figure 12 shows the spatial extent of the NLINE model for the north end of Keewaydin Island. The model covered a beach length of approximately $2.5 \mathrm{~km}$ (between Florida Department of Environmental Protection (DEP) monuments R-90 to R-98

Collier County, FL.). The beach bathymetry for NLINE was represented by a grid of contours and cross shore gridlines. The represented contours in both models included 14 contours ranging from a berm elevation of $+1.5 \mathrm{~m}$ to an offshore

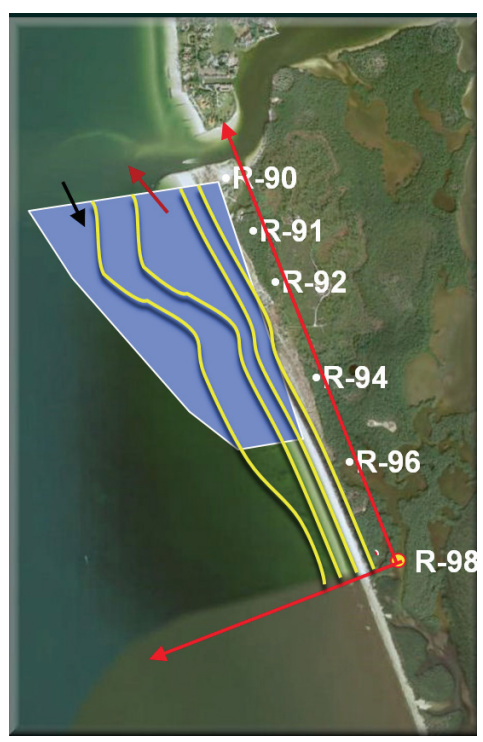

Figure 12. Schematic of NLINE model coverage for downdrift beach evolution modeling contour of $-8 \mathrm{~m}$. The offshore extent was set beyond the typical offshore distance to depth of closure of approximately $-4.5 \mathrm{~m}$ to include the effects of offshore bathymetry on wave transformation. The contour spacing was varied. Close contour spacing was used to provide higher resolution in the nearshore area where the sediment transport rates are highest and significant elevation changes over relatively short time intervals, and wider spacing was used further offshore where limited change occurs. The NLINE model grid consisted of 198 gridlines at a spacing of 43 feet. Figure 12 shows the model coverage and coordinate system.

\section{Model calibration and verification}

The NLINE model was calibrated and verified with documented beach change. The NLINE model simulated the beach evolution between DEP monuments R-90 to R-98 for the 24-year time period from 1985 to 2009. The NLINE simulations were done to evaluate the long-term beach change and post fill erosion rates for three previous inlet dredging and beach fill projects to provide calibration and verification of the model capability to simulate the long-term beach evolution. Model calibration was 
done through comparison of shoreline change from the 1985 beach fill conditions with the 1988 and 1992 post fill conditions. Figures 13 show model calibration results. Model verification were based on simulations from 1992 to 1998 and 2003 to 2008, simulating the performance of the 1992 and 2003 beach fill projects. In 2003 an erosion control project consisting of 3 nearshore T-groins along the immediate 400 meters downdrift of the inlet were constructed at the same time of inlet dredging and beach fill event. The three T-groins were included in the 2003 verification simulation. Figure 14 shows model verification results for the 2003 beach fill project. Please note that in all cases the vertical scale in these figures is exaggerated relative to the horizontal distance scale.
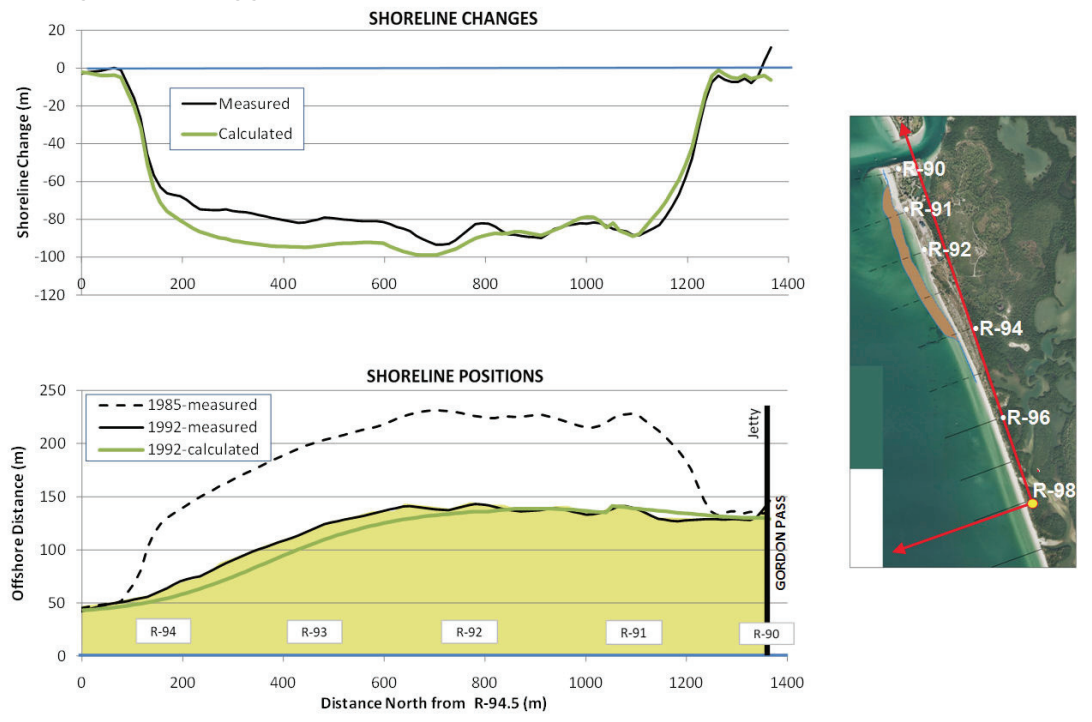

Figure 13. NLINE model calibration of shoreline change (1985-1992)

The calibrated model results correlated well with changes quantified through field measurements and observations and hence verified the prediction capability of the model. The model was then used to evaluate design alternatives while minimizing impacts to adjacent beach areas. The results show agreement with the beach fill dispersion and shoreline recession rates in the project area (R-90 to R-92) and the downdrift beach (R-92 to R-98). The model results indicate the model's capability to simulate long-term shoreline change in a complex beach environment near a tidal inlet.
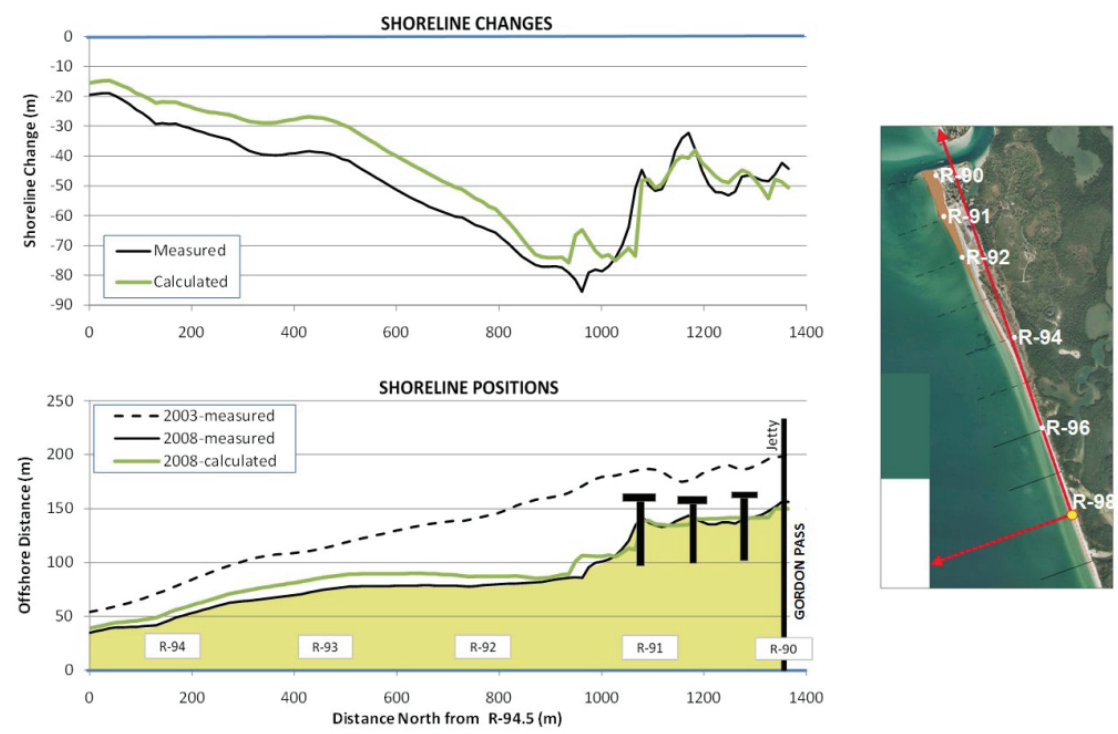

Figure 14. NLINE model verification of shoreline change (2003-2008) 


\section{Performance and design of erosion control structures}

The calibrated model results correlated well with changes quantified through field measurements and observations and hence verified the prediction capability of the model. The model was then used to evaluate the function of the 2003 erosion control structures and extend the erosion control structures to the ebb shoal attachment downdrift of the inlet, as illustrated in Figure 8. Based on the monitoring results of the existing T-groins and the modeling results, Phase II of the erosion control project has been designed to create a transition between the T-groins in Cell 1 and the sand bypass attachment bar at Cell 3 (Figure 9) where the limited sand supply from natural bypassing occurs. Sensitivity analysis of the predicted shoreline response to various breakwater parameters was done using the Boussinesq wave model Bouss2D (Nwogu and Demirbilek, 2001) for detailed wave-structure interaction and the NLINE model for long-term beach response.

Various erosion control structure design alternatives were evaluated including two nearshore T-groins, two offshore breakwater segments, and two offshore breakwater segments with two short groin sections. The selected alternatives also including the fill placement only alternative from the maintenance dredging of Gordon Pass. The selected alternatives were included in a 6-year simulation for shoreline and beach response to average and highly active wave climate. The NLINE results were used to optimize the design through assessment of the projected beach response and potential downdrift impacts. The modeling and purpose of the sensitivity analysis were done to optimize the size of the breakwater segments, the width of gaps between segments and groin sections, breakwater segment locations, geometry, and breakwater permeability related to wave transmission through or over the breakwater. Adjusting these parameters is important to achieve the project objectives and design shoreline. One of the main design objectives was to create a transition beach between Cell 1 and Cell 3 (Figure 9) where the sand bypass attachment bar is approximately located. The transition should be achieved by a limited salient beach response from the structures while minimizing downdrift effects through the permeability of the proposed structures. The permeability of the structures is adjusted based on crest elevation and gaps between the groins and breakwater sections. The results of the 6-year simulations were used to evaluate each alternative and optimize the final proposed design.

The final design included construction of two detached breakwaters and two short groins. Figure 15 shows the beach fill shoreline projected as part of the ongoing beach fill placement from the federal inlet maintenance and beach fill project. This figure also shows the proposed permeable breakwater segments and groins to achieve a smoother beach plan form from Cell 1 to the location where the bypass bar attaches south of R-92. The figure shows the

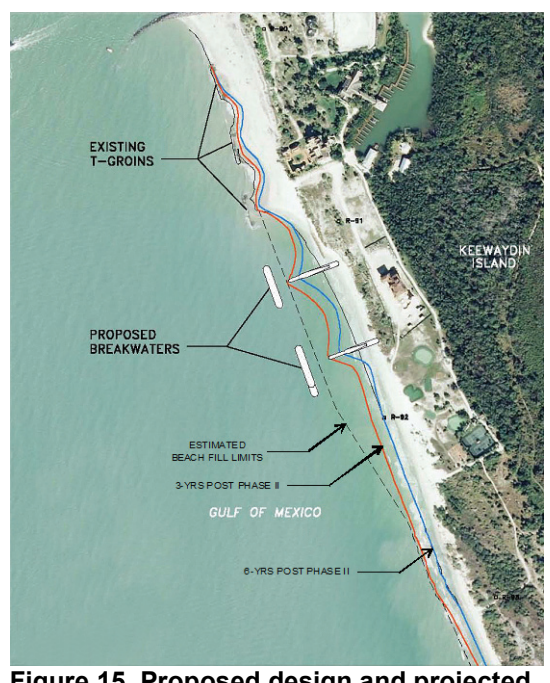

Figure 15. Proposed design and projected shoreline response

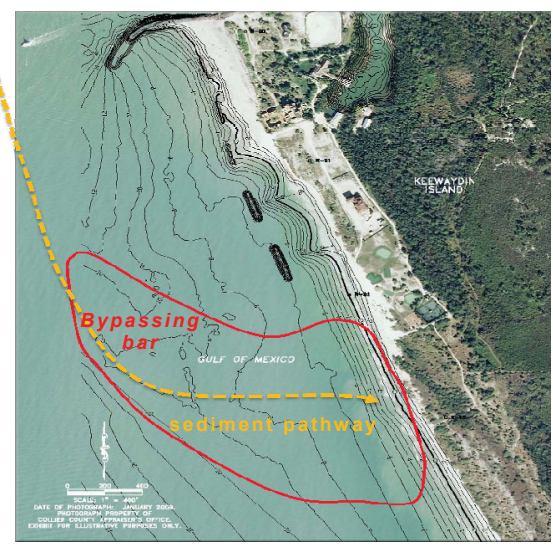

Figure 16. Proposed design, beach response and inlet sand bypassing projected shorelines at 3 and 6 years post construction for typical wave conditions provided sand is placed under the federal inlet maintenance project. 
Figure 16 shows the final design and the projected shoreline response for beach conditions 6 years post construction of the scheduled beach fill and proposed erosion control structures. The figure also shows the approximate location of the sediment pathway and the sand bypassing attachment bar. The location of the project results in a gradual transition from the jetty, south toward the natural bypass attachment bar, approximately 1 to $1.3 \mathrm{~km}$ south of the inlet. While the combination of Phase I and II of the North Keewaydin Erosion Control Project does not entirely relieve the north end of the island from the cumulative impacts from the long-term maintenance of the Gordon Pass Navigation Channel and other inlet changes, the erosion control project reduces the high sediment transport gradients that have resulted from past inlet management practices. This places the immediate downdrift shoreline to Gordon Pass in a much more manageable position for the future.

\section{CONCLUSIONS}

This paper discusses evaluation of inlet management practices in southwest Florida following a methodology based on several case studies. The methodology is developed to evaluate tidal inlet evolution and morphologic responses to natural and anthropogenic changes. The general approach is based on modeling and analysis of coastal processes on a large scale in time and space to develop boundary conditions that may then be used as input to detailed modeling on a scale appropriate for evaluating specific local project objectives. The methodology includes modeling of regional hydrodynamics, detailed process modeling of wave/current interactions, and long-term morphology evaluation using the Inlet Reservoir Model or beach evolution models. This approach provides a broad understanding of regional processes, localized processes at subject inlets including long-term inlet evolution, and response to human-made alterations to natural systems.

The case study for Gordon Pass, Naples, Florida is discussed in detail to describe an application to this methodology. The case study used both historic and recent topographic and bathymetric surveys, aerial photographs and other information to document the morphologic evolution of Gordon Pass, its bay and shoal system. The data were used to set up a series of numerical models that simulate the inlet tidal hydrodynamics and coastal processes that drive inlet morphological changes and adjacent beach evolution. The modeling results correlated well with changes quantified through field measurements and observations, which validates the prediction capability of this methodology. The study was used to evaluate the long-term evolution of the inlet's ebb shoal and adjacent beaches. The case study assessed the effects of the navigation improvements including the jetty construction and cumulative dredging on the ebb shoal evolution and downdrift beach response. The modeling and analysis provided tools to evaluate the inlet downdrift erosion problem and design an erosion control project to improve the inlet sand management.

The four case studies along Southwest Florida gulf coast, including Gordon Pass, provided application to a general mythology that allows for modeling long-term morphology of inlet and beach evolution for large scale in time and space. The combination of 2D flow/sediment transport models with the simple long-term morphology models provides a practical tool to evaluate long-term inlet evolution and to evaluate alternatives for improving management of sand resources of tidal inlets for reduced impacts to adjacent beaches.

\section{ACKNOWLEDGMENTS}

This study was conducted by Humiston and Moore Engineers, Naples, Florida. The authors would like to acknowledge the support of Comax Partners, LP throughout the design and permitting process which necessitated this analysis. The authors would also like to acknowledge Dr. Nicholas Kraus and the Coastal Inlets Research Program, U.S. Army Corps of Engineers (USACE) for the Inlet Reservoir Model developments and technical support. 


\section{REFERENCES}

Buttolph, A. M., C. W. Reed, N. C. Kraus, N. Ono, M. Larson, B. Camenen, H. Hanson, T. Wamsley, and A. K. Zundel. (2006). Two-dimensional depth-averaged circulation model CMS-M2D: Version 3.0, Report 2: Sediment transport and morphology change. Coastal and Hydraulics Laboratory Technical Report ERDC/CHL TR-06-09. Vicksburg, MS: U.S. Army Engineer Research and Development Center.

Dabees, M. A. and Kamphuis, J.W.(2000) NLINE, Efficient Modeling of 3D Beach Change" Proceedings, 27th International Conference on Coastal Engineering, Sydney, Australia, ASCE, pp2700-2713

Dabees, M. A. and Kraus, N. C. (2004): Evaluation of Ebb-Tidal Shoals as a Sand Source for Beach Nourishment: Proc. 17th Conf. on Beach Preservation Technology FSBPA, Tallahassee, FL, 21pp

Dabees, M. and Kraus, N. C. (2005): General Methodology for Inlet reservoir Model Analysis of sand Management Near Tidal Inlets. Proc. Coastal Dynamics 2005, 14pp.

Dabees, M. A. and Kraus, N. C. (2008): Cumulative Effects of Channel and Ebb Shoal Dredging on Inlets in Southwest Florida. Proc. International Conf. on Coastal Engineering 2008, pp. 23032315.

Dabees, M. A., and Moore, B. D. (2011) Inlet Evolution Modeling of Multiple Inlet Systems In Southwest and Central Florida. Journal of Coastal Research, Special Issue 59, In Print.

Dabees M. A., Moore, B.D., and Humiston, K. (2011) Evaluation of Tidal Inlets Channel Migration and Management Practices in Southwest Florida, Proc. Coastal sediments 2011, WS, In Print.

Humiston \& Moore (2007) Wiggins Pass Study, Phase II, Hydrodynamic and Sand Transport Modeling, Technical Report, Prepared for Collier County, Florida.

Kraus, N.C. (2000a); Reservoir Model of Ebb-tidal Shoal Evolution and Sand Bypassing, J. Waterway, Port, Coastal and Ocean Eng., 126(6), 305-313.

Kraus, N.C. (2000b): Prediction of Ebb-Shoal Evolution and Sand Bypassing. Proc. 13th Conf. on Beach Preservation Technology, FSBPA, Tallahassee, FL, 268-280.

Nwogu, O. and Demirbilek, Z. (2001). Bouss-2D: A Boussinesq wave model for coastal regions and harbors", ERDC/CHL TR-01-25, U.S. Army Engineer Research and development Center, Vicksburg, MS. 